C. Jácome ${ }^{1,2}$, A. M. Pereira ${ }^{1,2,3}$, R. Amaral ${ }^{1,2,4}$, M. Alves-Correia ${ }^{3}$, R. Almeida ${ }^{1,2}$, S. Mendes ${ }^{1}$, J. Almeida Fonseca ${ }^{1,2,3,5}$, INSPIRERS group

\title{
The use of remote care during the Coronavirus disease 2019 pandemic: a perspective of Portuguese and Spanish physicians
}

${ }^{1}$ Center for Health Technology and Services Research (CINTESIS), Faculty of Medicine, University of Porto, Porto, Portugal ${ }^{2}$ Department of Community Medicine, Information and Health Decision Sciences (MEDCIDS), Faculty of Medicine, University of Porto, Porto, Portugal

${ }^{3}$ Allergy Unit, CUF Porto Hospital and Institute, Porto, Portugal ${ }^{4}$ Department of Cardiovascular and Respiratory Sciences, Porto Health School, Polytechnic Institute of Porto, Porto, Portugal ${ }^{5}$ Medicina, Educação, Investigação, Desenvolvimento e Avaliação (MEDIDA), Porto, Portugal

\section{KEY WORDS}

Telehealth; telemedicine; teleconsultation;

COVID-19; chronic diseases; outpatient follow-up.

\section{Corresponding author}

Cristina Jácome

Center for Health Technology and Services Research (CINTESIS)

Faculty of Medicine

Universidade do Porto

Rua Dr. Plácido da Costa

Porto 4200-450, Portugal

ORCID ID: 0000-0002-1151-8791

E-mail: cristinajacome.ft@gmail.com

Doi

10.23822/EurAnnACI.1764-1489.184

\begin{abstract}
Summary
This study aimed to characterise how the follow-up of outpatients was done during the first months of COVID-19 pandemic by a multidisciplinary group of physicians involved in an asthma mHealth project. A cross-sectional study based on a web survey was conducted. The survey was sent to 123 physicians working at secondary care centres of Portugal and Spain, that participate in the INSPIRERS project. A total of 65 physicians completed the survey (53\% response rate). They had a mean of 18 (11) years of clinical practice and $14 \%$ were residents. More than half were allergists (58\%), 22\% pulmonologists and 20\% paediatricians. Most were working in Portugal (89\%) and in public hospitals (88\%). All were conducting consultations: $71 \%$ presential (median [p25, p75] duration 30 [20, $30] \mathrm{min}), 91 \%$ telephonic $(15[10,20] \mathrm{min})$ and $20 \%$ video consultations $(20$ $[10,28] \mathrm{min})$. The median duration of presential consultations was significantly higher than pre-COVID-19 $(20[20,30] \mathrm{min} ; p=0.021)$. From the physicians conducting video consultations, $92 \%$ were allergists and only $54 \%$ considered that their institution provided adequate conditions. The physicians of the INSPIRERS group used telephonic consultations as the main alternative to presential ones and $1 / 5$ used video consultations. These results suggest the need to rethink clinical follow-up services for outpatients in the near future increasing the use of telemedicine, especially video consultations.
\end{abstract}

\section{IMPACT STATEMENT}

Physicians used telephonic consultations as the main alternative to presential ones and $1 / 5$ used video consultations. An increased use of telemedicine, especially video consultations, should be considered for clinical follow-up services. 
C. Jácome, A. M. Pereira, R. Amaral, et al.

\section{Introduction}

The COVID-19 pandemic impacted dramatically on health care systems worldwide, with resources of the national health services mainly focused on the monitoring and management of patients with COVID-19 (1). Assessment and management of patients with chronic diseases have been extremely affected (2). Typically, patients with chronic diseases are seen 1-3 months after an initial visit and/or starting treatment and then every 3-12 months thereafter $(3,4)$. Due to COVID-19 restrictions and in the light of evidence that patients with chronic diseases could be more likely to experience severe complications due to COVID-19 infection (5), face-to-face contacts were reduced. Chronic disease management has moved towards telephone triage and remote care wherever possible to minimise the risk of COVID-19 transmission $(6,7)$. In mild cases, telephone screening might be adequate, but video consultations, by allowing additional visual cues and examination, were more strongly suggested (8). However, it is currently unknown if these alternative strategies to presential care were used and their feasibility in clinical practice.

Studies from Canada and USA reported the experience of allergy/immunology clinics during COVID-19 restrictions (9-11). Both telephone consultations (36.0-75.9\%) and video consultations $(17.0-56.4 \%)$ were used as alternatives to in-person visits $(0.2-6.6 \%)(9-11)$. It is possible that the same pattern occurred in Portugal and Spain, nevertheless these data are not yet available. To our best knowledge only a study in a Portuguese private allergy centre has reported the use of video consultation (15\%74\%) in April and May (12).

Thus, this study aimed to characterize how the follow-up of outpatients was done during the first months of COVID-19 pandemic by a multidisciplinary group of Portuguese and Spanish physicians involved in an asthma mHealth project.

\section{Materials and methods}

\section{Study design}

This is a cross-sectional quantitative study with a web-based survey applied to physicians participating in the INSPIRERS project (POCI-01-0145-FEDER-029130). The INSPIRERS is an asthma mHealth project, whose main aims are the development and evaluation of a mHealth app to measure and improve medication adherence in adolescents and adults with persistent asthma (13). This study followed the principles of the Declaration of Helsinki and the General Data Protection Regulation. All participants gave their online informed consent at the beginning of the survey: when accessing the link participants were presented with an introduction with the study purposes, duration of the survey and guarantees of confidentiality. If they agreed with the study procedures, they were asked to click on a confirmation button to proceed to the survey. This study is reported according to the
Strengthening the Reporting of Observational Studies in Epidemiology (STROBE) guidelines (14).

\section{Participants}

All 123 physicians that were involved in the studies of the INSPIRERS project (including allergists, pulmonologists, and paediatricians) were invited to participate. These physicians worked on 34 secondary care centres of Portugal and two of Spain. There were no other eligibility criteria.

\section{Data collection}

The web-survey, implemented in the Google ${ }^{\mathrm{TM}}$ Forms platform, was available between May $28^{\text {th }}$ and June $11^{\text {th }}$, during the Portuguese calamity period (15). The link to the survey was sent by e-mail. The survey included questions about physicians' characteristics (age, sex, medical specialty, years of clinical practice, setting), clinical practice before the pandemic and at the date of the survey completion (the type of consultations: presential, telephonic and video consultation, duration and mean number of patients seen per week).

\section{Statistical analysis}

Descriptive statistics were used to characterise the sample. The normal distribution of each variable was assessed by Kolmogorov-Smirnov test and visual analysis of histograms. The duration of presential consultations before and after COVID-19 were compared with Wilcoxon tests. Duration of consultations as well as the mean number of patients seen per week were compared across the 3 types of consultations using the Friedman test. Statistical analyses were performed using IBM SPSS Statistics version 26.0 (IBM Corporation ${ }^{\mathrm{TM}}$, Armonk, NY, USA). The level of significance was set at 0.05 .

\section{Results}

From the 123 invited, 65 physicians completed the survey (53\% response rate). They had a mean (SD) age of 46 (13) years old and were mostly female (60\%). They had between 2 and 40 years of clinical practice (mean [SD] 18 [11]), with 14\% being residents. More than half were allergists (58\%), 22\% pulmonologists and $20 \%$ paediatricians. Most physicians were working in Portugal (89\%) and in public hospitals (88\%). The participants' characteristics are presented in table I.

All physicians were conducting consultations: $91 \%$ carried out telephonic consultations, $71 \%$ presential, and $20 \%$ video consultations (table II). The duration of presential consultations during COVID-19 was superior to the duration before COVID-19 ( $\mathrm{p}=0.021$ ). During COVID-19, the three types of consultations were not found to be significantly different in terms of duration $(p=0.607)$ nor in the number of patients observed per week $(p=0.311)$. Physicians' characteristics such 
Table I - Participants' characteristics $(n=65)$.

\begin{tabular}{lcc}
\hline Characteristics & & \\
\hline Female & 39 & $(60 \%)$ \\
Age, mean (SD) & 45.7 & $(12.5)$ \\
Resident & 9 & $(14 \%)$ \\
Years of clinical practice, mean (SD) & 18.2 & $(11.1)$ \\
Medical Specialty & & \\
Allergy & 38 & $(58 \%)$ \\
Pulmonology & 14 & $(22 \%)$ \\
Paediatrics & 13 & $(20 \%)$ \\
Public setting & 57 & $(88 \%)$ \\
Country and region & \\
Portugal & & \\
$\quad$ North & & \\
$\quad$ Centre & 21 & $(32 \%)$ \\
$\quad$ Algarve & 12 & $(19 \%)$ \\
Lisbon & 4 & $(6 \%)$ \\
Islands (Madeira/Azores) & 16 & $(25 \%)$ \\
Spain & 2 & $(3 \%)$ \\
Galicia & & \\
Madrid & 3 & $(5 \%)$ \\
\hline
\end{tabular}

Data presented as $\mathrm{n}(\%)$, unless otherwise indicated; athree with missing data. as age, sex and years of clinical practice were not found to be different across the types of consultation.

Most physicians reported that both telephonic consultations and video consultations were performed always (51\%) or preferentially $(32 \%)$ at the health institution, although could also occur at their home or other places (11\%). From the 13 physicians conducting video consultations, 12 were allergists and only half $(n=7)$ considered that their institution provided the necessary means. Video consultations were performed mostly using specific platforms provided by the hospital $(n=6)$ and a cross-platform messaging (WhatsApp $\mathrm{n}=7$ ). Other platforms were also used: Google ${ }^{\mathrm{TM}}$ Meet $(\mathrm{n}=3)$, $\operatorname{Skype}^{\circledR}(\mathrm{n}=2)$, or $\operatorname{Zoom}^{\circledR}(\mathrm{n}=1)$.

\section{Discussion}

To our knowledge, this is the first study characterising the use of remote care to follow-up patients during the COVID-19 pandemic by a multidisciplinary group of Portuguese and Spanish physicians. We found that telephonic consultations were used across the three medical specialties as alternatives to in-person consultations and that video consultations were used by onefifth of physicians, mainly by allergists.

Telephonic consultations (91\%) were frequent in the analysed period. In previous studies in Canada and USA, telephonic consultations were also the main alternative to in-person consultations (36\% and 75.9\%) (9-11). Yet, in all three studies, the proportion of in-person consultations was much lower $(0.2$ -

Table II - Characterization of consultations during COVID-19 pandemics, including stratification by medical specialty $(n=65)$.

\begin{tabular}{|c|c|c|c|c|c|c|c|c|}
\hline \multirow{2}{*}{ All, n (\%) } & \multirow{2}{*}{\multicolumn{2}{|c|}{$\begin{array}{l}\text { Before COVID-19 } \\
\text { Presential } \\
\text { Consultations }\end{array}$}} & \multicolumn{6}{|c|}{ During COVID-19 } \\
\hline & & & \multicolumn{2}{|c|}{$\begin{array}{l}\text { Presential } \\
\text { consultations }\end{array}$} & \multicolumn{2}{|c|}{$\begin{array}{l}\text { Telephone } \\
\text { consultations }\end{array}$} & \multicolumn{2}{|c|}{ Video consultations } \\
\hline Mean duration, in minutes & 20 & {$[20,30]$} & 30 & {$[20,30]^{*}$} & 15 & {$[10,20]$} & 20 & {$[10,28]$} \\
\hline Mean number of patients, per week & - & & 16 & {$[10,26]$} & 25 & {$[14,40]$} & 5 & {$[2,15]$} \\
\hline Mean duration, in minutes & 20 & {$[15,30]$} & 30 & {$[20,30]$} & 15 & {$[10,20]$} & 20 & {$[11,29]$} \\
\hline Mean number of patients, per week & - & & 20 & {$[12,39]$} & 30 & {$[20,50]$} & 5 & {$[2,17]$} \\
\hline Pulmonology, n (\%) & 14 & $(100 \%)$ & 11 & $(79 \%)$ & 14 & $(100 \%)$ & 1 & $(7 \%)$ \\
\hline Mean duration, in minutes & 20 & {$[20,30]$} & 25 & {$[20,30]$} & 15 & {$[10,20]$} & 5 & \\
\hline Mean number of patients, per week & - & & 10 & {$[5,20]$} & 20 & {$[8,30]$} & 10 & \\
\hline Mean number of patients, per week & - & & 10 & {$[9,24]$} & 20 & {$[13,28]$} & - & \\
\hline
\end{tabular}

Data presented as median [p25, p75], unless otherwise indicated; ${ }^{*} \mathrm{p}<0.05$ between consultations before COVID-19 and presential consultations during COVID-19. 
6.6\%) than the one observed in our study (71\%) (9-11). However, the previous studies were conducted immediately after the implementation of COVID-19-related restrictions (between March $16^{\text {th }}$ and May $8^{\text {th }}$ ), while our study was conducted later (May $28^{\text {th }}$ until June $11^{\text {th }}$ ), in a period when health services were slowly trying to restart usual services. Additionally, the epidemiology of COVID-19 was also different between the Canada and USA and Portugal/Spain, with Portugal having the lowest proportion of cases per 100000 inhabitants (16).

The proportion of physicians using video consultations (20\%) was lower than expected considering other studies, being at the lower range limit observed at allergy/immunology clinics in the period post-COVID-19 (17\% to 74\%) (9-12). Yet, if we considered results per medical specialty, allergists are closer to the expected range (32\%), while pulmonologists and paediatricians performed video consultations much less $(7 \%$ and $0 \%$, respectively). However, we need to interpret these proportions in the light of the very low use of video consultations before COVID-19. A previous study conducted in 2016 by the American Medical Association, showed the low use of telemedicine for patient interactions among allergists (6.1\%), paediatricians $(11.8 \%)$ and pulmonologists (other internal medicine subspecialties $17.3 \%)$, which contrasted with radiology (40\%), psychiatry $(28 \%)$ and cardiology (24\%), among others (17). In a report of the Portuguese TeleHealth National Centre, analysing the use of video consultations between 2017 and 2019, only paediatrics were among the most engaged specialties, but mostly restricted to paediatric cardiologic (18). Despite the low percentages, we can speculate the frequency of video consultations increased during COVID-19 pandemic, as it has been seen across distinct health care systems (19), including the Portuguese National Health Service $(12,20)$. However, with the data collected at only one-time point, we are not able to assess how this proportion evolved. Nevertheless, the readiness of health institutions to implement video consultations is probably one of the factors contributing for the low use of this remote care strategy. Other technical issues such as bandwidth of hospital networks may have limited the adoption of this type of consultation. Of note, only half of the physicians conducting video consultations considered that their institution provided them all the necessary means. The physicians' experience with video consultations before COVID-19 might also have played a relevant role.

This study has limitations that should be acknowledged. Its cross-sectional design does not allow us to make any inference on the evolution of the proportion of each type of consultation nor possible differences in terms of health outcomes. Replicating the current study in the future, for example during the second wave of the COVID-19 epidemic, would allow to estimate the fluctuations in the different types of consultations and assess its effectiveness. Data were collected directly from physicians and did not identify the patient diagnosis (e.g., asthma, drug allergy, primary immunodeficiencies, etc.) or sociodemographic characteristics (age, education, digital literacy). Therefore, even though the selected physicians have an interest in asthma care, future studies should access if there are differences in the adoption of consultation types for patients with asthma and patients with other diseases, and also if they depend on the patient-physician relationship established ( $1^{\text {st }} v s$ follow-up consultation). Additionally, other physician and setting characteristics (e.g., medical specialty, conditions provided by the healthcare centre) should be explored in larger samples. This could be important to guide practical strategies of remote care. It would be also interesting to explore the patient perspective regarding access to remote care, as well as patients' and physicians' experience and satisfaction. Only physicians collaborating with INSPIRERS project were invited to participate, with most working in Portugal, and as these physicians are engaged with a mHealth research project, they may be more open to remote care in comparison with others. Thus, the results presented cannot be generalised to Portuguese physicians, and even less to Spanish physicians.

\section{Conclusions}

The physicians of the INSPIRERS group in the context of the COVID-19 pandemic used telephonic consultations as the main alternative to presential ones, although one-fifth also used video consultations. These results suggest the need to rethink clinical follow-up services for outpatients in the near future increasing the use of telemedicine, especially video consultations.

\section{Fundings}

This work was funded by ERDF (European Regional Development Fund) through the operation POCI-01-0145-FEDER-029130 ("mINSPIRE - mHealth to measure and improve adherence to medication in chronic obstructive respiratory diseases-generalisation and evaluation of gamification, peer support and advanced image processing technologies"), co-funded by the COMPETE2020 (Programa Operacional Competitividade e Internacionalização) Portugal 2020, and by Portuguese Funds through FCT (Fundaçâo para a Ciência e a Tecnologia).

\section{Acknowledgments}

We thank the physicians of the INSPIRERS group.

\section{Conflict of interests}

The authors declare that they have no conflict of interests. 


\section{References}

1. World Health Organization. COVID-19 significantly impacts health services for noncommunicable diseases. Available at: https://www.who. int/news/item/01-06-2020-covid-19-significantly-impacts-health-services-for-noncommunicable-diseases. Last access date: 11/01/2020.

2. Hartmann-Boyce J, Mahtani K. Supporting people with long-term conditions (LTCs) during national emergencies. CEBM 2020. Available at: https://www.cebm.net/covid-19/supporting-people-with-long-term-conditions-ltcs-during-national-emergencies/. Last access date: 10/28/2020.

3. Global Initiative for Chronic Obstructive Lung Disease. Global strategy for prevention, diagnosis and management of COPD. Available at: https://goldcopd.org/gold-reports/. Last access date: 11/01/2020.

4. van den Bemt L, Schermer T, Smeele I, et al. Monitoring of patients with COPD: A review of current guidelines' recommendations. Respir Med 2008;102:633-41.

5. Williamson EJ, Walker AJ, Bhaskaran K, et al. Factors associated with COVID-19-related death using OpenSAFELY. Nature 2020;584:430-6.

6. European Respiratory Society. COVID-19 and asthma. Available at: https:/www.ersnet.org/the-society/news/covid-19-and-asthma. Last access date: 11/01/2020.

7. Shaker MS, Oppenheimer J, Grayson M, et al. COVID-19: Pandemic Contingency Planning for the Allergy and Immunology Clinic. J Allergy Clin Immunol Pract 2020;8:1477-88.e5.

8. Beaney T, Salman D, Samee T, Mak V. Assessment and management of adults with asthma during the covid-19 pandemic. BMJ 2020;369:m2092.

9. Zhu R, Kim H, Jeimy S. Appointment characteristics during COVID-19 restrictions: A Canadian allergy/immunology centre perspective. J Allergy Clin Immunol Pract 2020;8:2837-8.

10. Ramsey A, Yang L, Vadamalai K, Mustafa SS. Appointment characteristics in an allergy/immunology practice in the immediate aftermath of COVID-19 restrictions. J Allergy Clin Immunol Pract 2020;8:2771-3.
11. Mustafa SS, Yang L, Mortezavi M, Vadamalai K, Ramsey A. Patient satisfaction with telemedicine encounters in an allergy and immunology practice during the coronavirus disease 2019 pandemic. Ann Allergy Asthma Immunol 2020;125:478-9.

12. Morais-Almeida M, Sousa CS, Barbosa MT, Aguiar R, Benito-Garcia F. Telehealth: The future is now in allergy practice. J Allergy Clin Immunol Pract 2020;8:2836-7.

13. Jácome C, Guedes R, Almeida R, et al. mINSPIRERS - Estudo da exequibilidade de uma aplicação móvel para medição e melhoria da adesão à medicação inalada de controlo em adolescentes e adultos com asma persistente. Protocolo de um estudo observacional multicêntrico. Rev Port de Imunoalergologia 2018;26:47-61.

14. Vandenbroucke JP, von Elm E, Altman DG, et al. Strengthening the Reporting of Observational Studies in Epidemiology (STROBE): explanation and elaboration. Int J Surg 2014;12:1500-24.

15. Diário da República n. ${ }^{\circ} 85 / 2020$, 30 Suplemento, Série I de 2020-0430. Available at: https:/data.dre.pt/eli/declretif/25-A/2020/07/15/p/ dre. Last access date: 11/01/2020.

16. Worldometer. Available at: https://www.worldometers.info/coronavirus/. Last access date: 11/01/2020.

17. Kane CK, Gillis K. The Use Of Telemedicine By Physicians: Still The Exception Rather Than The Rule. Health Affairs 2018;37:1923-30.

18. Serviços Partilhados do Ministério da Saúde. Consultas de Telemedicina no SNS 2017 - 2019. Available at: http://www.cnts. min-saude.pt/wp-content/uploads/2020/02/Atividade_Teleconsulta_2017_2019_V2.pdf. Last access date: 11/01/2020.

19. Mann DM, Chen J, Chunara R, Testa PA, Nov O. COVID-19 transforms health care through telemedicine: Evidence from the field. J Am Med Inform Assoc 2020;27:1132-5.

20. Serviço Nacional de Saúde. Consultas em telemedicina. Available at: https://www.sns.gov.pt/monitorizacao-do-sns/consultas-em-telemedicina/. Last access date: 11/01/2020. 